\title{
Cultural Factors Associated With Criminal Male Behavior And Inmate Population
}

\author{
Patricia Martínez-Lanz \\ Universidad Anahuac México \\ Director of the Interdisciplinary Research Center \\ Alejandro Sánchez-Guerrero \\ Universidad Anahuac México \\ Interdisciplinary Research Center \\ Martha Patricia Hernández-Valdez \\ Universidad Anahuac México \\ Interdisciplinary Research Center
}

\begin{abstract}
Over the last decade, crime has reached unprecedented levels causing violent death in Mexico. To establish factors that potentially can facilitate crime, as well as the status of emotional wellbeing presented in prison population, the present study was realized with a sample composed of 299 inmates of the Federal Center for Social Reinsertion in Oaxaca, Mexico. The questionnaire was specifically developed, designed and applied to evaluate this population, analyzing sociodemographic factors and four Likert scales: substance consumption (drugs and alcohol), domestic violence and depressive symptoms. Reliability was adequate (Cronbach's Alpha $=.703$ ) and the instrument validity showed appropriate relations between the reagents of each scale. Results showed -through Chi Square analysis- statistically significant differences in the correlations between sociodemographic factors, domestic violence, addictions and depressive symptoms. Results reported that most of inmates were between 28 and 47 years old (51.8\%), with a low educational level (elementary school $42.5 \%$ ), in consensual union (42.5\%), high and severe levels of alcohol consumption $(43.5 \%$ of the cases) and reported presence of high and severe level of depression $(28.9 \%$ of the cases). The results are part of a national study of all Federal Centers for Social Reinsertion System in Mexico, in order to developed intervention strategies used in prison to prevent crime.
\end{abstract}

Keywords: Delinquency, Addictions, Violence, Depression, Crime, Criminal Behavior.

INTRODUCTION: PENITENTIARY SYSTEM IN MEXICO.

Mexico ranks in seventh place about prison population at global level [1]. The national rate in 2016 was about 173 imprisoned people for every 100 thousand residents; in United States of America the rate was 693 people, while in Canada was 114 people in the same condition.

According with Ministry of the Interior [2] data, there were a 236,886 imprisoned people in the country, 191 thousand 631 for common jurisdiction crimes and 45 thousand 255 people for federal jurisdiction crimes. About imprisoned population, 68.1\% were between 18 and 39 years old; $94.1 \%$ were scholarly, and $72.1 \%$ had basic education ${ }^{1}$.

1 In August 2017, the Institute for Criminal Policy Research, World Prison Brief, University of London (http://www.prisonstudies.org/country/mexico) estimated 208689 inmates in Mexico (rate of 169). It ranked the country in 10 th place worldwide of states with highest number of inmates. 
National Penitentiary System infrastructure is constituted by 379 penitentiary centers: 17 Federal Social Reinsertion Centers (CEFERESOS), 291 State Social Reinsertion Centers and 71 municipal prisons. On 2016, the National Human Rights Commission [3] developed an evaluation in order to measure custodies indicators:
a. Inmate integrity ${ }^{2}$
b. Dignified residence ${ }^{3}$
c. Governance conditions ${ }^{4}$
d. Social reinsertion ${ }^{5}$
e. Attention to specific requirements ${ }^{6}$

Specifically, CEFERESO No. 13 located in Oaxaca, with a population about 2 thousand 227 inmates ( 2 thousand 520 inmates as total capacity), obtained a 6.7 grade (the national average was 7.2), which places it in 16th of 19 total units. In this sense, important items are:

- Right to public health in imprisoned people.

- Inadequacy of prevention and attention of violent incidents programs.

- Material and hygiene conditions inside prison facilities (income and bedrooms).

- Labor activities and training, as well as educational and sports activities.

- Attention to elderly people, indigenous, inmates with HIV / AIDS.

- Insufficiency programs about substance consumption, prevention and voluntary detoxification.

The last Survey of Imprisoned Population [4] made by the National Institute of Statistics and Geography (INEGI), identify several factors presented in this CEFERESO:

- Nationally, the inmate's participation in educational programs is mostly low, presenting percentages about $31.3 \%$ of people enrolled; however, in Oaxaca, $5.9 \%$ of population is joining educative schedules.

- Although, other activities are more frequent such as body training, recreation, reading and religious worship; these activities are lower than the country average: 85.6 versus $53.7 \%$.

- Conflict situations and violence are part of daily life in penitentiary centers; the inmates with the higher percentage of direct conflicts lived in CEFERESO No. 13 (also above the national average for conflicts with custodies).

- In order to understand the familiar dynamic of inmates in CEFERESO No. 13 it is reported:

- Lowest percentages of visitors (friends or family) was reported in the last year (26\% had visits, when the national average in man inmates is $75 \%)$. Perhaps this phenomenon is influenced by the visitor's origin: $83.4 \%$ come from another state, $9.2 \%$ come from another city in the state and only $4.3 \%$ live in the same city.

(http://www.prisonstudies.org/highest-to-lowest/prison-population-

total?field_region_taxonomy_tid=All\&=Apply)

${ }^{2}$ Housing capacity and total population, distribution and separation of inmates in case of mixed centers, care and health services, general supervision, prevention and attention to violent incidents, torture and / or abuse.

${ }^{3}$ Facilities, material and hygiene conditions, as well as sufficient and quality food.

${ }^{4}$ Legal regulations of each Center, security and custody, disciplinary sanctions, self-government, illegal activities, extortion and bribes, staff training.

${ }^{5}$ Integration of legal file; classification, technical committee operation; work activities, training for occupation, education and sports; anticipated freedom and inmates connection with society.

${ }^{6}$ Women, older adults, indigenous people, people with disabilities, HIV / AIDS or addictions. 
- This is related with the low percentage of conjugal visits in the last year $(5.1 \%$ of inmates refer this appointment).

- Family communication via telephone is the lowest nationally, only in $99.3 \%$ of cases communicate with family members once or twice a week.

- Low levels of labor activity were identified in CEFERESO No. 13: 4.8\% of inmates develop any type of occupation (versus $71.1 \%$ nationwide; this results are common in federal penitentiaries, unlike the statewide reports). In addition, only $26.2 \%$ of inmates admitted development of work skill during incarceration.

- Daily hours lived inside the prison cell performed important information in order to understand the impact on inmate's mental health. In the case of CEFERESO No. 13, 96.8\% of inmates passes between 19 and 24 hours in these conditions; similar percentages are reported by other CEFERESOS.

- A revealing fact about inmates familiar situation in National Penitentiary System, is the vulnerability conditions experienced with the caregivers in youth: in this CEFERESO, parent's alcohol consumption was higher than national average (34.4 versus 32.8\%), which is related with physical aggressions (17.2 vs. $16 \%)$, injuries (9.7 vs. $8.3 \%$ ) and sexual aggressions, showing a significant difference (2.3 vs. 1.5\%) (Figure 1):

Figure 1. Vulnerability conditions experienced by inmates with caregivers before age 15.

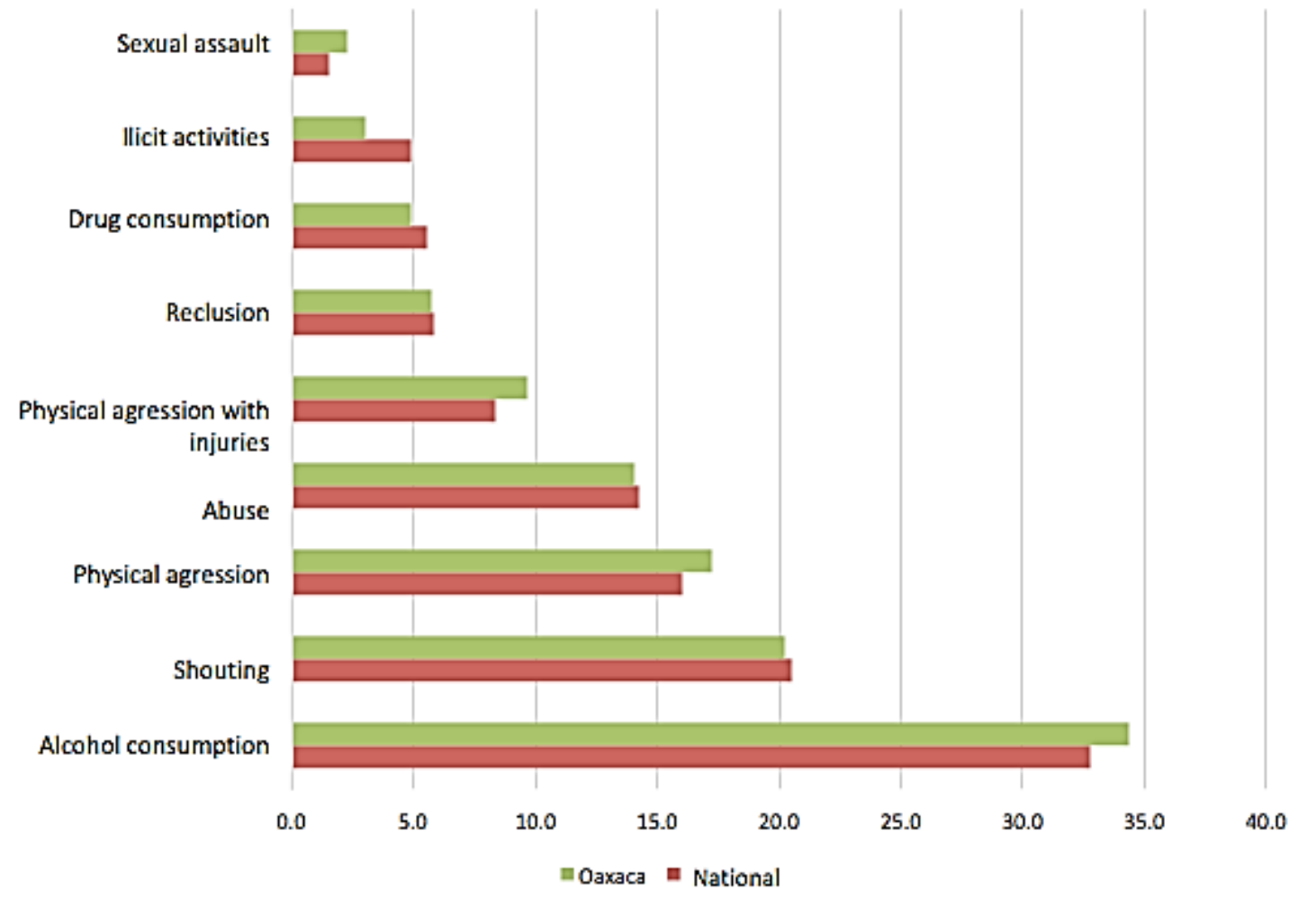

Source: Survey of the Imprisoned Population (ENPOL-INEGI, 2016).

The study at the Federal Social Reinsertion Center number 13 in Oaxaca, consisted on 299 selfapplication questionnaires developed specifically for this population, allowing recognition of sociodemographic factors and some scales about familiar and labor situation, substances consumption and domestic violence prior the arrest, as well as depressive symptomatology during imprisoning. A Cronbach's Alfa of .703 was obtained from a reliability analysis. An exploratory factor analysis showed that the scales were grouped satisfactorily in terms of symptoms. The information was analyzed with several methods of multivariate statistics, such as principal component analysis, correlation analysis and contingency tables. 


\section{Sociodemographic data}

\section{RESULTS.}

In CEFERESO No.13 inmate's age responds to an economically active period (94.3\%), and a high percentage (58\%) is located in the first age ranges (Figure 2).

Figure 2. Population age ranges.

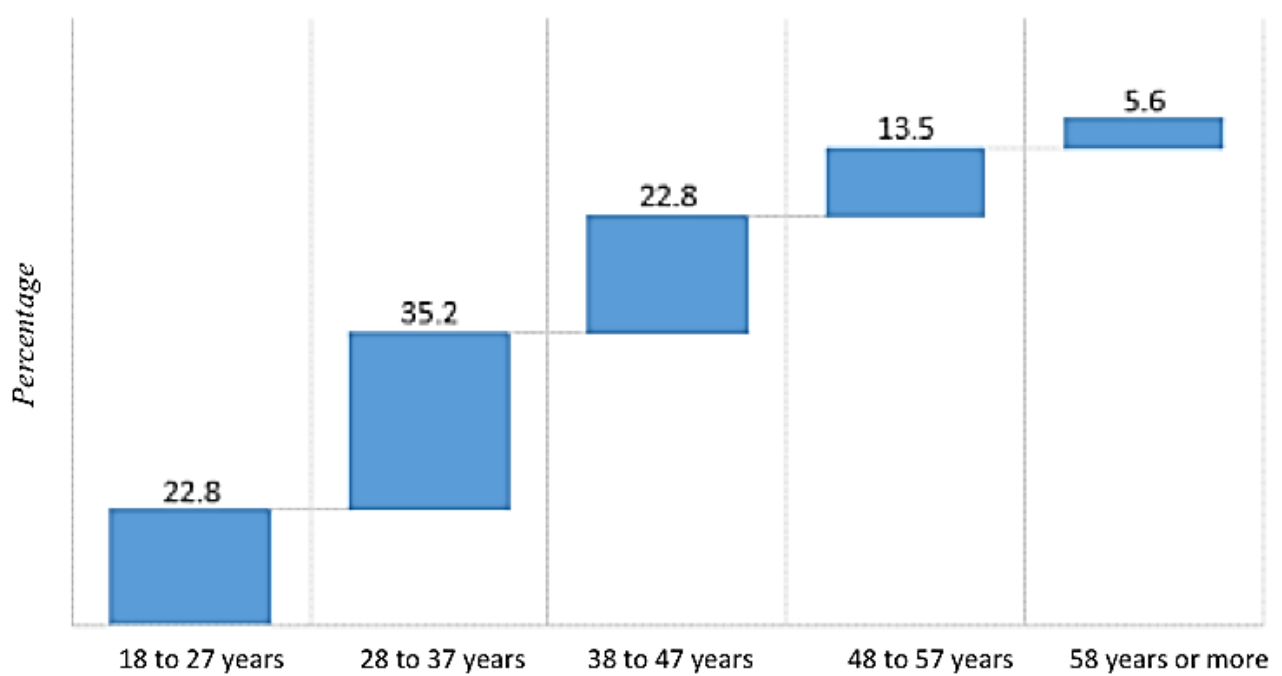

Age ranges

The age range in which inmates admitted drug consumption in the month prior imprisonment, presents an important influence: the older they reported the consumption, the numerous is drug use. However, after the 38 years, pattern consumption decreases with the number of drugs consumed.

Figure 3. Substance consumption by age range.

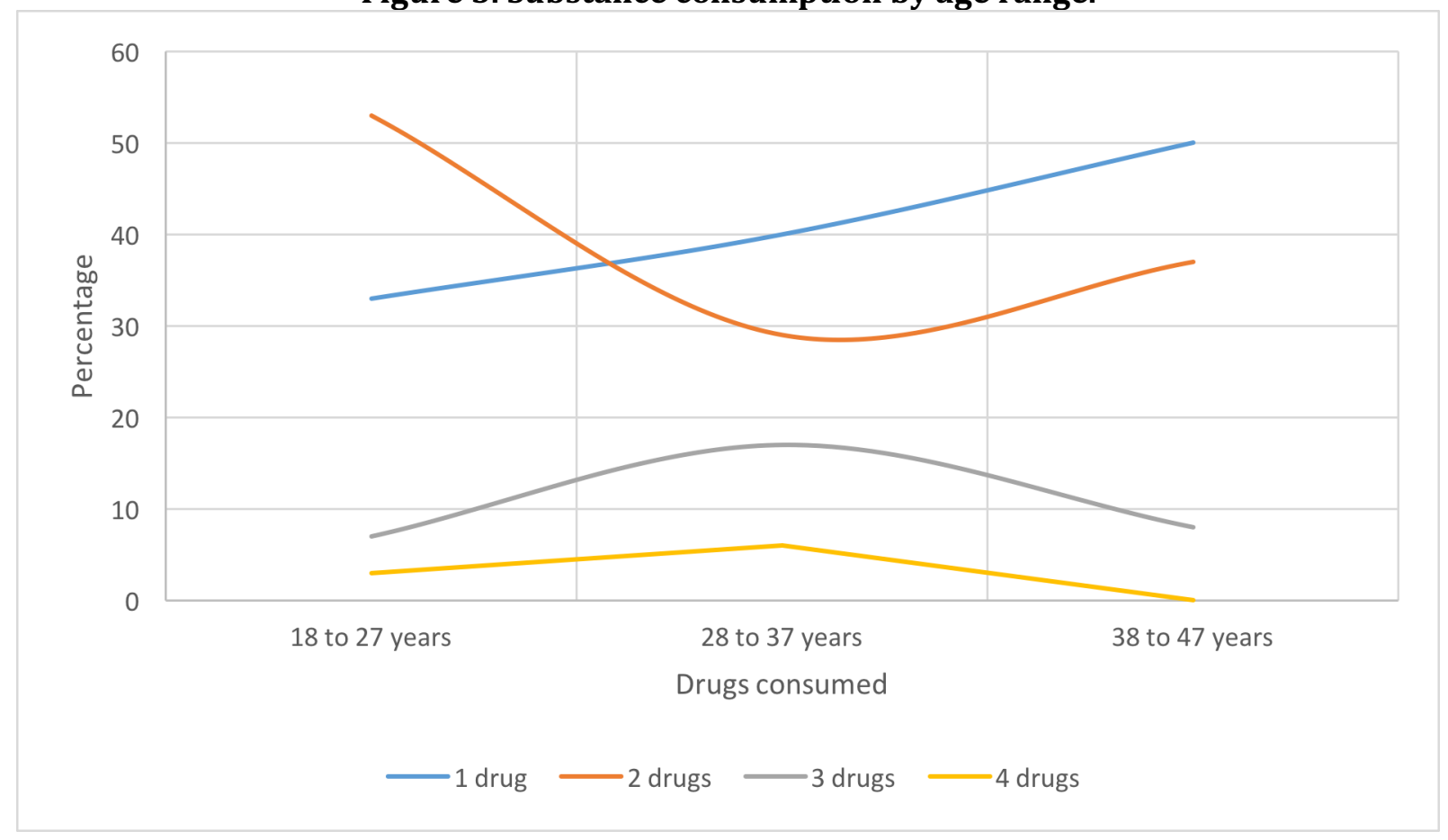


About substance consumption, it is observed:

- As age increases, the use of marijuana is less likely in last month (Chi square $p=0.019$ ); although, dependence risk tends to increase with age.

- Highest levels of marihuana consumption in last month are related with homicide and drug trafficking.

- Cocaine consumption in last month before imprisonment is related with inmates age (Chi square $p=0.043$ ): on intermediate ages (28 to 37 years and 38 to 47 years) increases the probability of consumption, and higher risk of drug dependence is found in 28 to 37 years range.

- The crime associated with several cocaine consumption in the last month, is theft.

Concerning the inmate's age and substances consumption (Figure 3), puberty and adolescence are stages of intense growth. In this period, normal (and desirable) development process auspicious the autonomy and interpretation of new roles, judging habits and lifestyles learned, exploring new sensations, testing familiar and social limits, managing impulsive output and adoption of risk behaviors with disruptive ${ }^{7}$ and violent acts; the commission of infractions, criminal acts and the substance consumption [6].

The relation between age ranges and committed crimes shows that youngest inmates committed kidnapping, while forgery is related with older ages.

Almost 3 of each 4 inmates in CEFERESO No. 13 were in a marital status that supposed cohabitation (76.2\%) in terms of marriage, as well as free union in addition to live with children (61.1\% and $52.8 \%$, respectively). This data is important to calculate family impact of imprisonment, as $75 \%$ of inmates were the economic support in the family. It is assumed that only $23.8 \%$ lived alone (Figure 4 ).

The imprisonment violates personal development in closest and intimate existence; convict desires to maintain connection with his family. The prisoner is exposed to adverse circumstances, being the family a psychologically irreplaceable escape valve. On the other hand, in the outside family life suffers several situations in material and environmental conditions, revealing minimum levels of well-being, even more when inmate provided economic support [5].

The most important demand to face by prison administration is the family environment maintenance, understanding this primary nucleus as also vulnerable like inmate's psychological structure [5].

${ }^{7}$ Disruptive behavior is considered to be any disturbing or alarming act intended to frighten, confuse, disconcert, distract or interrupt to population, or pretend to disrupt some conditions in order to prevent its operation. 
Figure 4. Population marital status.

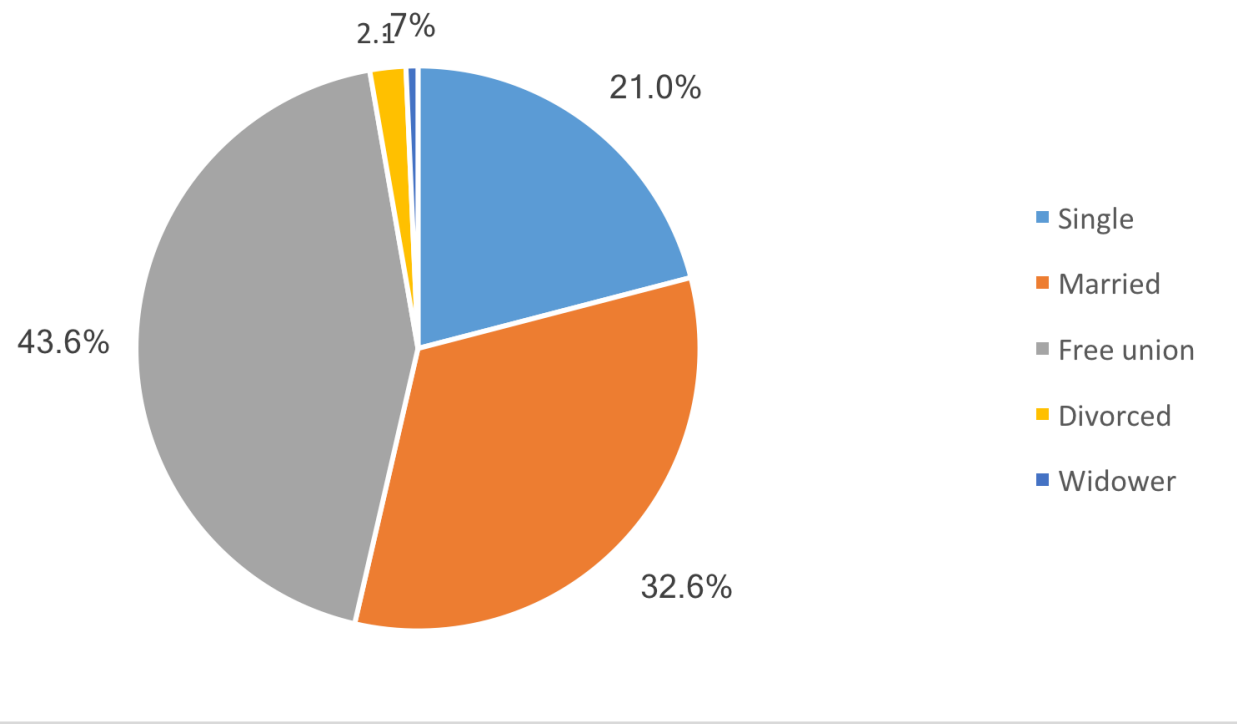

Scholarship level (Figure 5) tends to be low: 50.5\% had elementary education (maximum of 6 years of formal study) and 39.6\% reports middle education (up to 9 years of formal study). This variable is related $(\mathrm{p}=0.000)$ with the age of first work: youngest workers show lower levels of scholarship.

Figure 5. Population scholarship.

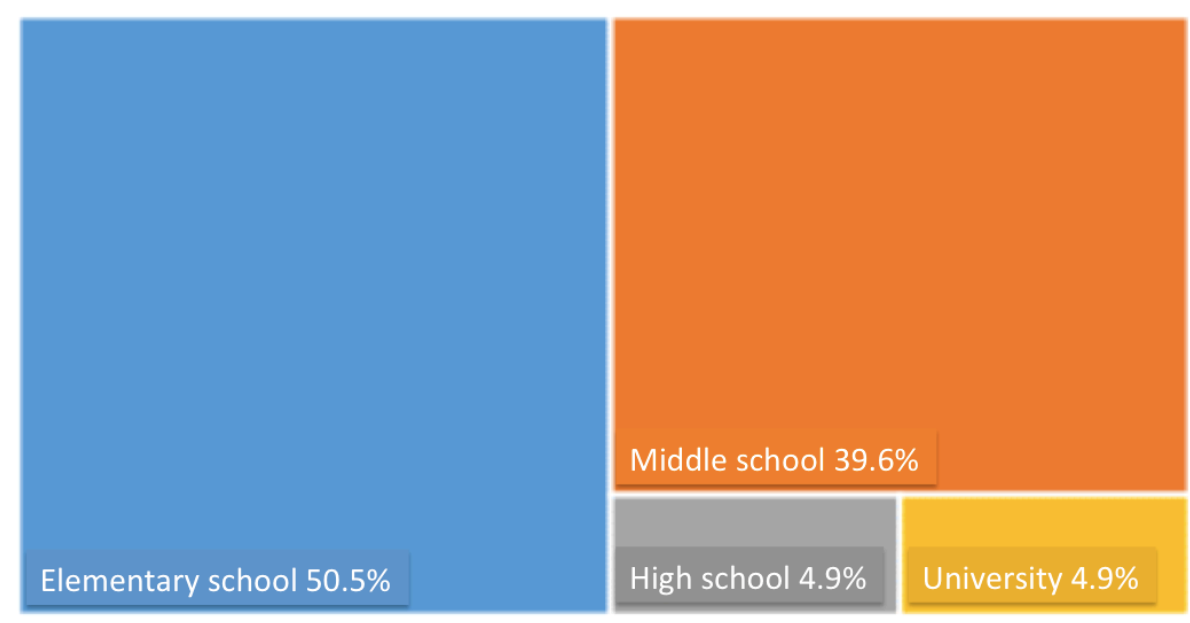

Kidnapping and homicide are associated with lower levels of scholarship; those related with higher levels of education are rape and forgery.

A significant association between academic failure and criminal behavior has been observed frequently [7]. Academic failure is related with the transmission of socially consensual norms; in this sense, with the impossibility of continuous education, the delinquency is clearly promoted. Another important result is the predictive power of antisocial behavior presented in caregivers, over the antisocial behavior of children.

\section{Emotional and familiar situation}

Comparing inmate's legal situation, the analysis shows: with a largest number of years in imprisonment situation, depression levels tend to be lower; this phenomenon could be related with an adjustment behavior to the prison habitat; in cases with more than 21 years in detention, levels of depression tend to increase (Anova $p=0.014$ ) (Figure 6). 
Prison as a closed area demands an adaptive effort by inmates, generating affective, emotional, cognitive and perceptive distortions as consequence. Adaptive effort produces a "normal" life; this normality cannot be interpreted as a situation of well-being. The prison reveals the necessity of adaptation in order to recognize a tense, demanding and emotionally unstable atmosphere [5].

Significant levels of emotional anxiety, according to personal circumstances, follow prison entrance, inversely proportional to amount of knowledge about penitentiary environment. A correct comprehension about criminal atmosphere reduces emotional tension; the lack of knowledge significantly increases it [8].

Figure 6. Depression levels according to Sentence of imprisonment.

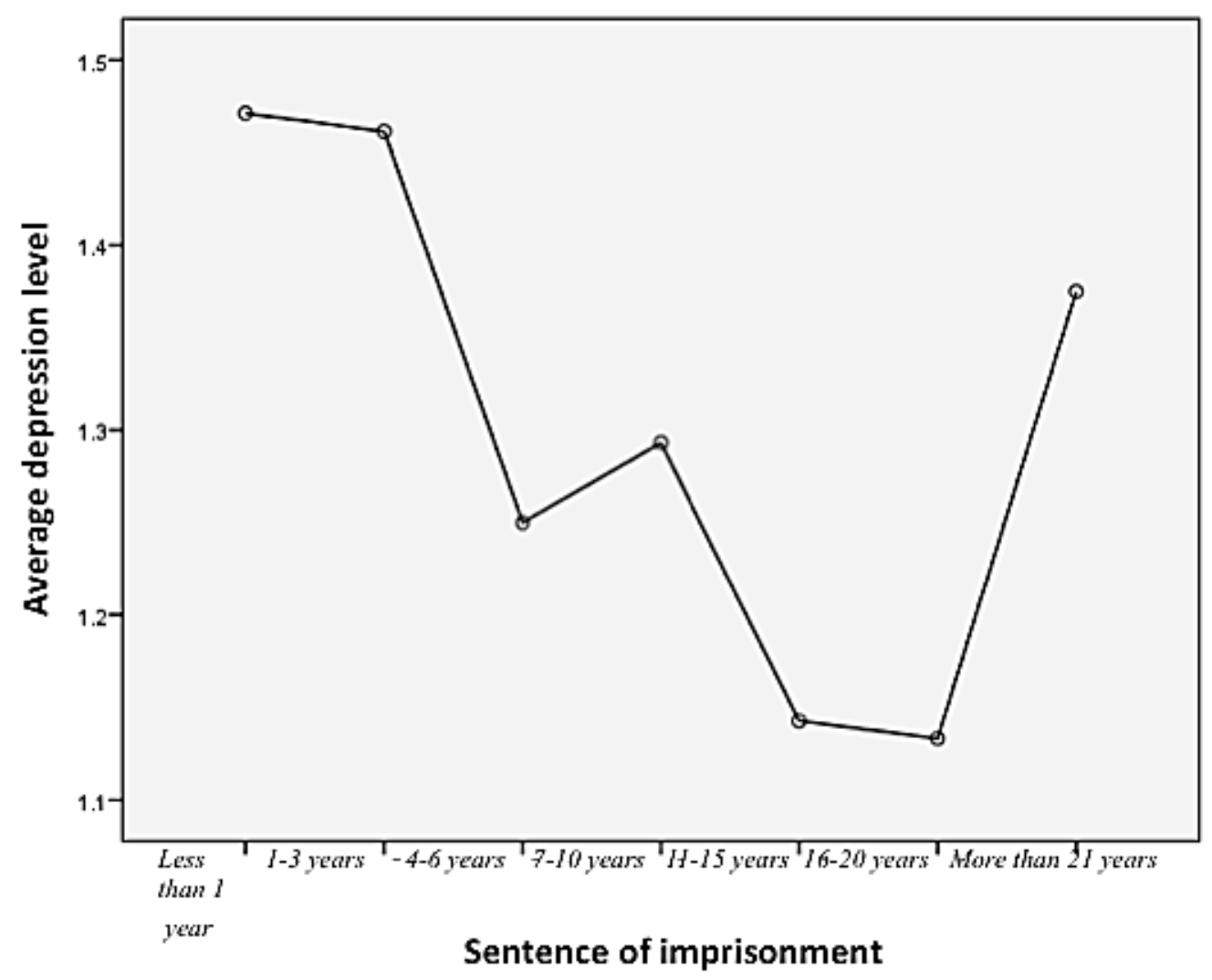

Inmate's depression levels prevailing during imprisonment increased according to domestic violence reported prior the prison entrance (Figure 7). 
Figure 7. Depression levels according to domestic violence.

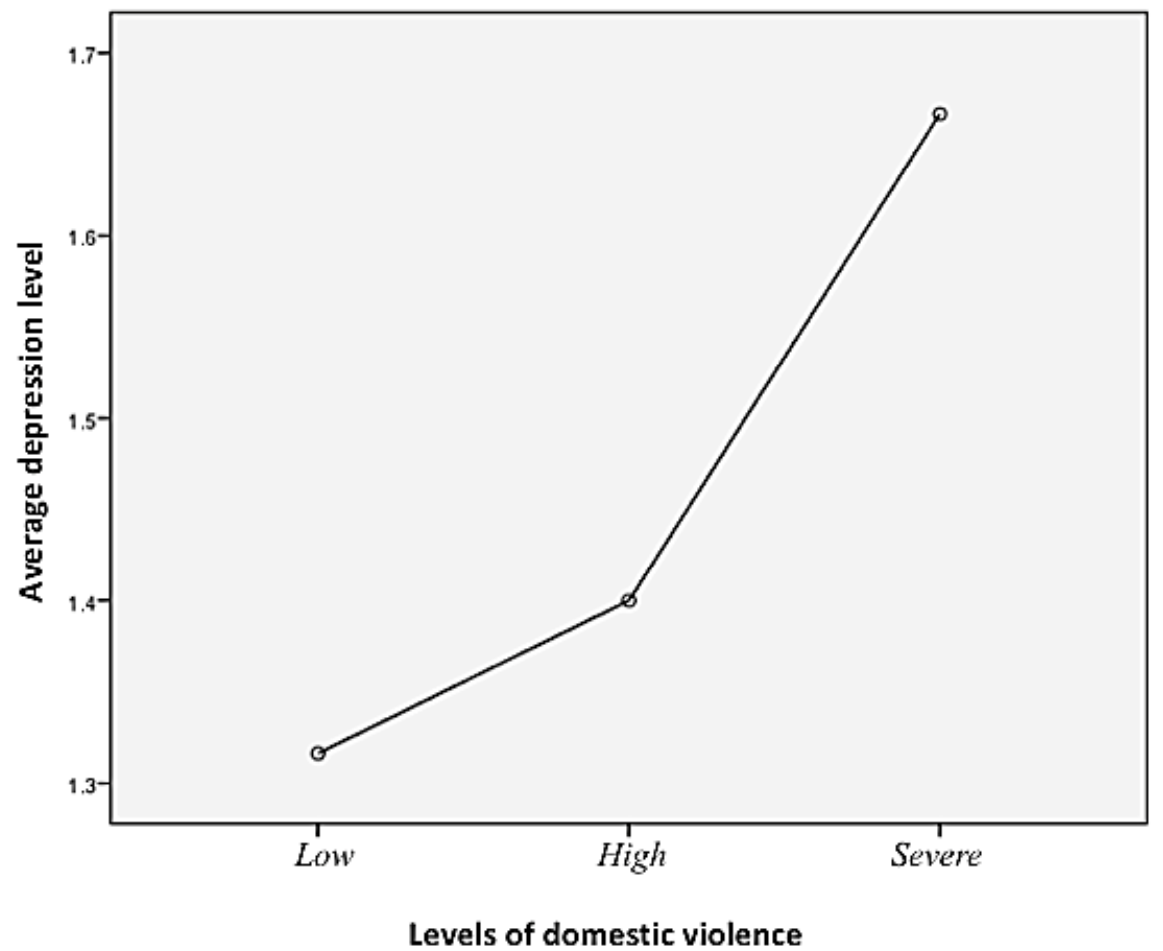

It has been identified family abuse as a risk factor for criminal behavior, although these behaviors are not necessarily violent. The proposal of different causes in the abuse and crime involves modeling, presence of insecure emotional attachment, hostile interpretations of neutral stimuli, desensitization to intense experiences, and negative coping styles [5].

The lack of supervision over children activities, showing punitive, permissive or inconsistent reactions, predicts delinquency. Different studies reveal an authority combined with affective support and normative control, as a promotion of self-control and social competence, while rigid and punitive styles (characterized by permissiveness or indifference) generates aggressive and anti-normative behaviors [9].

\section{Occupational situation prior imprisonment}

About quantity of jobs reported by inmates, in the last 10 years prior incarceration, an employment stability is assumed by the results obtained: $76.2 \%$ reported four jobs $(31.2 \%$ had a job); this is related with the entrance to prison as main reason of waiver $(63.5 \%)$. Both variables are related (chi square $\mathrm{p}=0.000$ ): Figure 8 shows $74.4 \%$ of inmates with the same job in the last 10 years (maximum level of job stability), lost it by imprisonment. This reason reported the highest percentage for each employment interval worked. 
Figure 8. Jobs in the last 10 years according to reason of waiver.

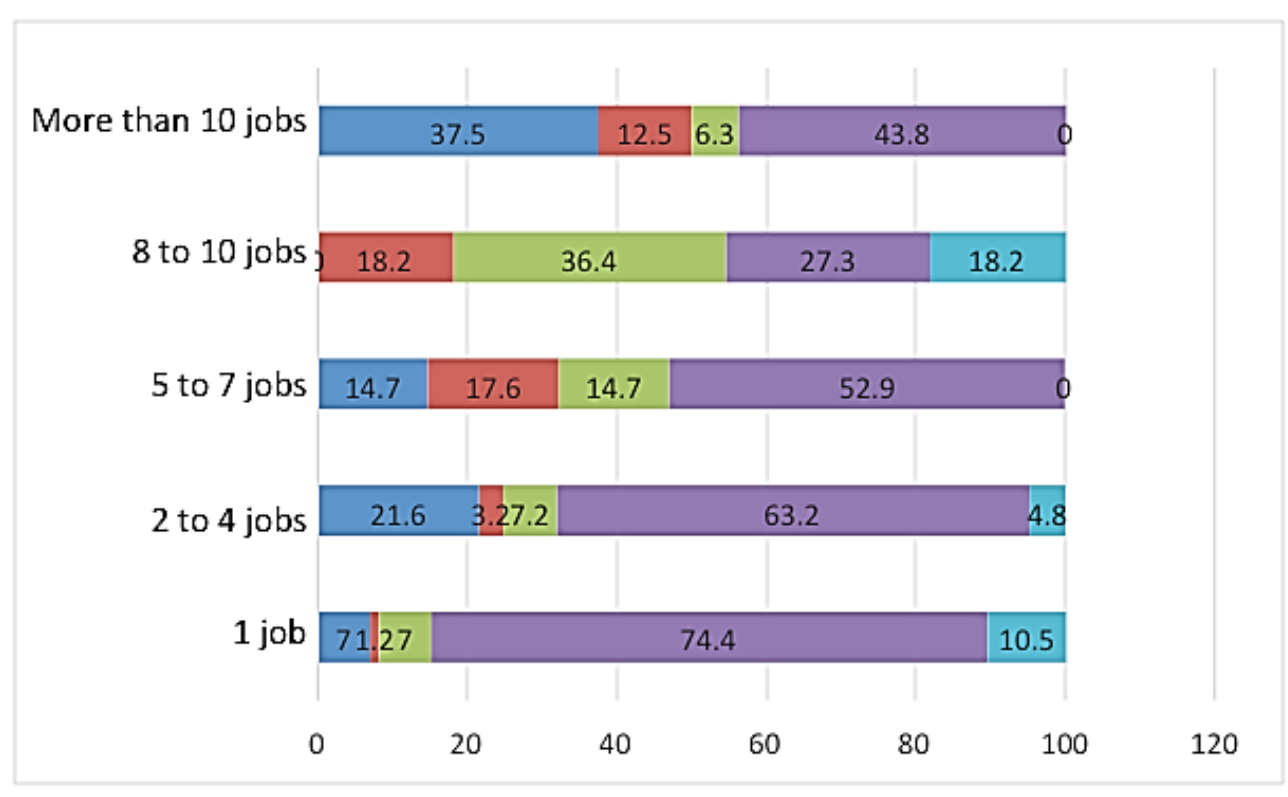

Waiver Dismissal Temporary job Imprisionment Other reason

Population is characterized by early insertion in work activities: $87.3 \%$ started to work before or at the age of 16, and almost 4 of 10 inmates worked at 12 years or younger (Figure 9).

Figure 9. Age of first job.

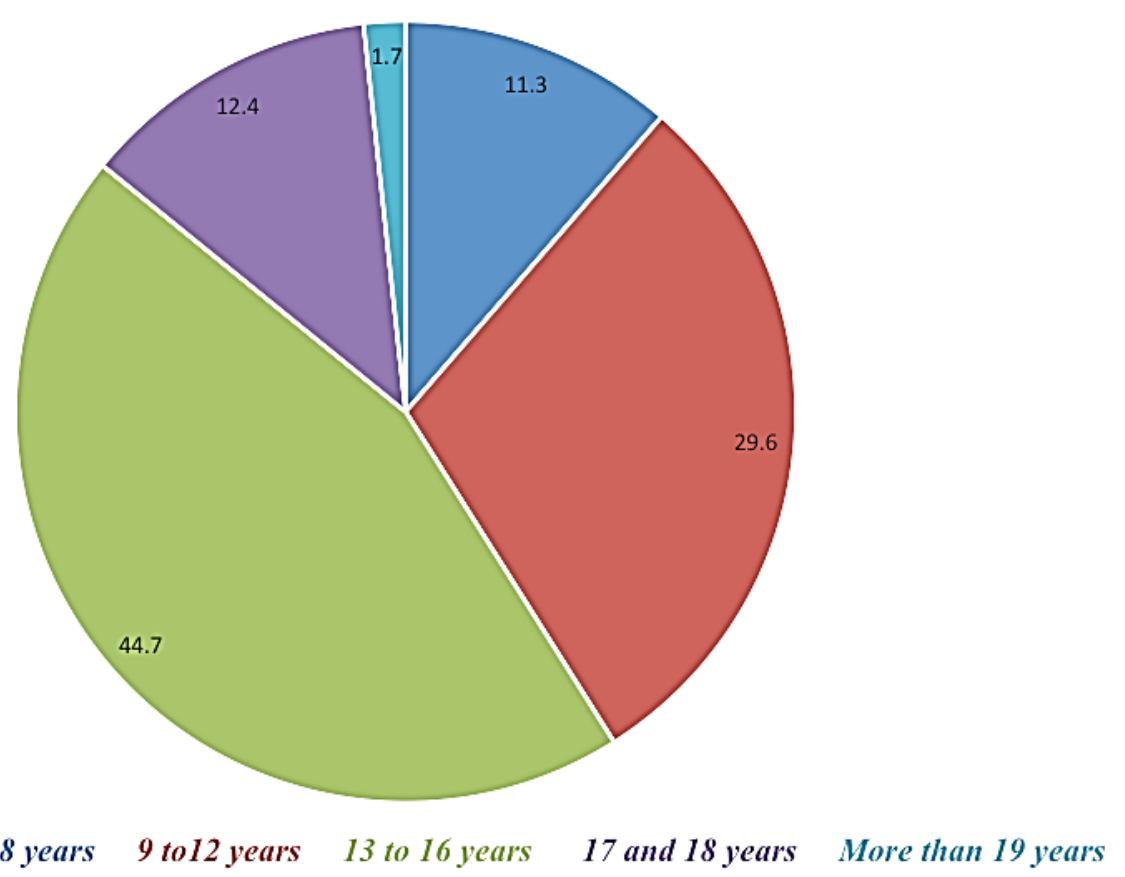

It is also observed relation between ages of first job and crime committed (chi square $\mathrm{p}=$ 0.043) (Figure 10). Earliest ages correspond to forgery (75\% started to work at 8 years or younger), homicide, theft and drug trafficking $(57.4,47$ and $39.1 \%$, respectively, at 12 years or less). 
Figure 10. Crime committed according to age of first job.

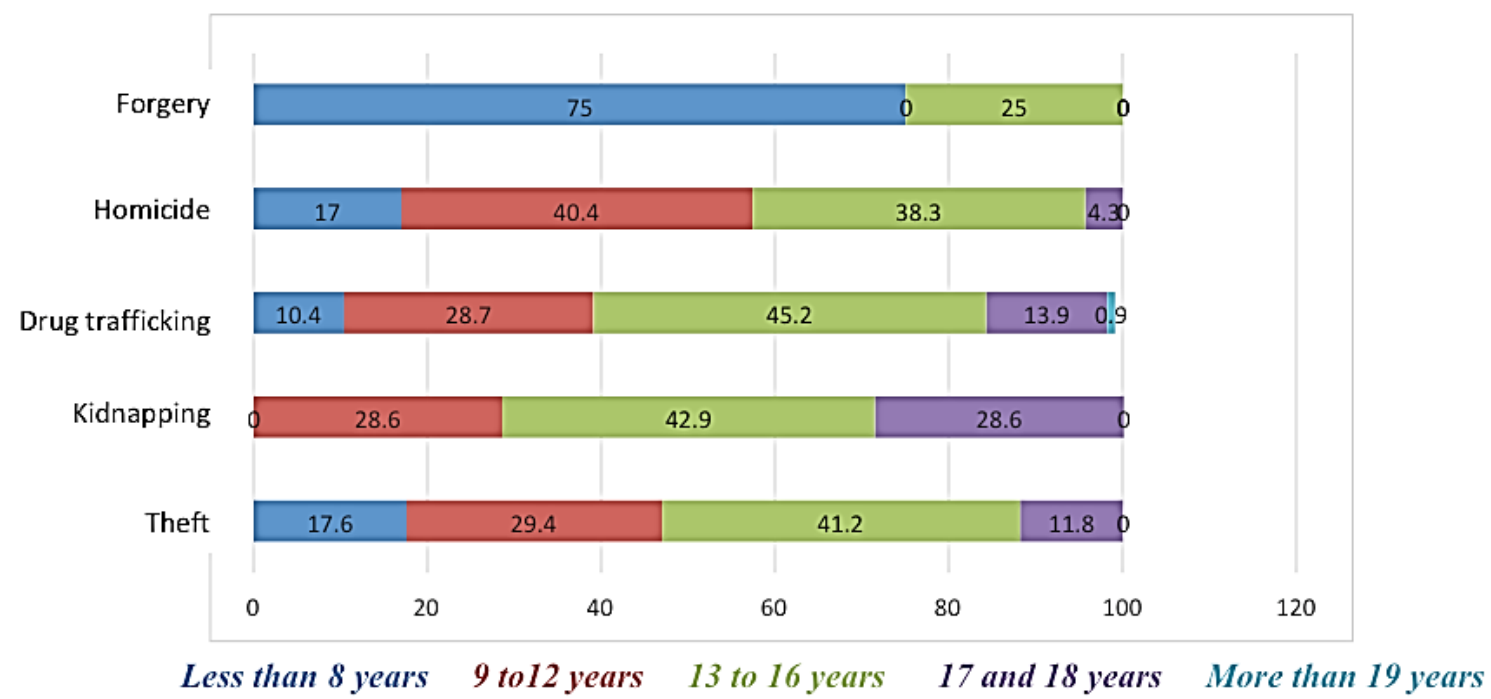

\section{CONCLUSIONS}

Risk factors are individual characteristics and conditions that increase possibility of harm [6]. Thus, substances consumption and domestic violence conformed facilitating elements in CEFERESO number 13 inmates (located in Oaxaca), based on sociodemographic characteristics explored for this study.

Regarding depressive symptomatology and adaptation to prison environment, prisionalization phenomenon on inmates is noticed. This process is originated as a direct consequence of imprisonment, trough the understanding of conduct code and values that sustains prison culture. It is, therefore, a behavioral adaptation [9]. This psychological technique allows environment adjustment, and consequently, coexistence.

As in any social action in order to prevent crime, the knowledge about risk factors allows the development of solutions, creating a unified system of social containers acting in a systematic way. It is also important to interfere on the most important social nucleus - the family -to precise strategies to know consequences of different phenomena such as isolation, frustration, domestic violence and substance consumption, which promote criminal behavior [10].

In general, living conditions prior imprisonment is reproduced by cultural factors founded within CEFERESO: it is possible to identify, for example, a parallelism in violence conditions on prison coexistence similar with familiar situations.

To observe the purpose of this institutions, a model focused on achieving social reintegration is developing; the analysis of these models determines facilitating factors for criminal behavior. In this sense, is desirable to observe existent program focuses on CEFERESO No. 13:

- A consistent implementation of addiction treatment program focused mainly on new inmates, allowing familiar participation with accompaniment strategy and emotional restructuring.

- Educational restructuration as inmate's goals, making initial diagnosis to elaborate a plan related with conditions and motivations of each inmate.

- To systematize structured programs about recreational, cultural and sports activities to motivate inmates to commit with themselves, allowing discipline around the activity.

- Promotion of conflict resolutions with innovative and creative proposals to provoke motivation and interests on inmates. 
- To establish a program focuses on reconciliation of family issues, restructuring social nucleus with inmate's support and participation of family network.

- Development of productive and educational activities to allow skills and necessary competences for set an occupation inside and outside the penitentiary center.

In colonies or minimum geographical areas with confined people, preventive actions proposed by Secretary of Prevention and Citizen Participation [6] conformed a prevention strategy for crime, establishing particular goals:

1. To fortify supportive children and youth policies, providing opportunity to join to educational system, ensuring permanence.

2. Development of prevention programs aimed at minors, to produce necessary skills to fight against negative environment influence.

3. Incorporation to municipal, state and federal levels work plans and preventive action, considering all phases of integral approach for family, in order to ensure impact on risk population.

4. Design and disseminate, through basic education, awareness campaign recommended by International Initiative of the World Health Organization (1993) with education in childhood, education in adolescence, family support, life skills (self-knowledge, empathy, assertive communication, alternative problem solving, critical thinking, emotion management, stress management).

5. Combine efforts with social actors, such as media, companies and civil society organizations to disseminate knowledge about social responsibility.

\section{References}

Moreno Pérez, Salvador (2017). Los centros penitenciarios en México. ¿Centros de rehabilitación o escuelas del crimen?, Carpeta informativa No. 70, abril de 2017. México: Cámara de Diputados. LXII Legislatura.

Secretaría de Gobernación (2016). Cuaderno mensual de información estadística penitenciaria nacional. México: SEGOB/Comisión Nacional de seguridad.

Comisión Nacional de Derechos Humanos (2016). Diagnóstico Nacional de Supervisión Penitenciaria 2016. México: CNDH, 650 p.

Instituto Nacional de Estadística y Geografía (2016). Encuesta Nacional de Población Privada de la Libertad (ENPOL) <https://www.inegi.org.mx/programas/enpol/2016/> [12 de junio de 2019]

Sobral, J., Romero, E., Luengo, M.A. y Marzoa, J.A. (2000). Personalidad y conducta antisocial: Amplificadores individuales de los efectos contextuales. Psicothema, 12, 661-670.

Lozano, A., Torres, P., \& Olivas, M. (2010). Factores Familiares que inciden en la Conducta Disruptiva y Violenta de Niños, Adolescentes y Jóvenes. Subsecretaría de Prevención y Participación Ciudadana.

Loeber, R., Farrington, D. P., Stouthamer-Loeber, M., Moffitt, T. E., \& Caspi, A. (1998). The development of male offending: Key findings from the first decade of the Pittsburgh Youth Study. Studies on Crime and Prevention, 7, 141-171.

Romero, E., Luengo, M.A. y Gómez-Fraguela, J.A. (2000). Factores psicosociales y delincuencia: Un estudio de efectos recíprocos. Escritos de Psicología, 4, 78-91.

Quevedo, E. A. (2018). El fenómeno de la prisionalización: complejo penitenciario Islas Marías/The prisonalization phenomenon: Islas Marías penitentiary complex. RICSH Revista Iberoamericana de las Ciencias Sociales y Humanísticas, 6(12), 336-360.

Rovira, M., Larrauri, E., \& Alarcón, P. (2018). La concesión de permisos penitenciarios. Revista electrónica de Ciencia Penal y Criminología, 20 (2), 1-26. 